\title{
Strategy of Redirection: What is it About?
}

\author{
Vadim V. Sdobnikov* \\ Nizhny Novgorod State Linguistic University \\ 31a Minin Str., Nizhny Novgorod, 603155, Russia
}

Received 13.02.2018, received in revised form 16.04.2018, accepted 26.04.2018

The article highlights the communicative situations of translation in which the strategy of redirection is used. The definition of the redirection strategy is given, and the gist of this strategy is explained. Examples of the redirection strategy application in both translation and interpreting are provided based on the communicative-functional approach to translation.

Keywords: strategy of redirection, translation, interpreting, communicative-functional approach.

DOI: 10.17516/1997-1370-0274.

Research area: linguistics, culturology.

\section{Introduction}

It is generally recognized that translation/ interpreting process follows a certain strategy chosen by a translator/interpreter on the basis of particular criteria. At the same time, Translation Studies knows neither universally acknowledged definition of translation strategy nor the wellestablished set of criteria we apply to select a translation strategy. Definitions of translation strategy vary from scholar to scholar. Some investigators argue that a strategy is a method, or procedure, used to solve a certain translation problem. For example, Ana Fernández Guerra, referring to Hans Krings, writes that translation strategies are usually defined as "the procedures leading to the optimal solution of a translation problem. The procedures or strategies based on comparative stylistics (Vinay y Darbelnet, Malblanc, Intravaia and Scavée), also used by other scholars (Vázquez Ayora, Newmark, ...), or the techniques suggested by Bible translators (Nida, Nida and Taber, Margot), intended to propose a metalanguage and to catalogue possible solutions in the task of translation" (Fernández Guerra, 2012: 5). The same vision of translation strategy is still popular among Russian translation scholars. Tatiana Volkova, among others, believes that translation strategy can be defined as "an infinite combination of professional, effective, dynamic, logically interrelated, successive universal and individual methods (translated by the author. V.S.)" (Volkova, 2010: 21). These methods are used to comprehend fully the Source Text (ST) and to produce the Target Text (TT) focused on the situational characteristics underlying translation and/or interpreting, text type, and the character of the perspective TT recipient (Volkova, 2010: 21). The opposite approach represents the hypothesis according to which translation strategy is a general approach

(C) Siberian Federal University. All rights reserved

* Corresponding author E-mail address: artist232@rambler.ru 
to translation, a kind of a translator's professional thinking that forms the basis for his/her actions (Komissarov, 2001: 356). The first group definitions seem to contradict the mere notion of "strategy", the latter implying a certain program of performing an activity while the second group definitions are too vague to be of any practical significance. It is also clear that criteria of selecting the appropriate translation strategy largely depend on how translation strategy is defined. In many cases, though, translation and/ or interpreting are performed without a second thought of any strategy whatsoever. It follows that defining the notion of "translation strategy" remains rather a theoretical issue than a practical one.

In our research (which claims to be of both theoretical and practical significance) we stick to the communicative-functional approach to translation. It implies that any translation act which is organized, performed or investigated must be placed in a certain context, environment, i.e. in a communicative situation, and must be viewed, assessed, and studied only with account of the situation characteristics. The communicativefunctional approach defines translation strategy as a general program of the translator's activity worked out on the basis of the general approach to translation in a specific communicative situation (CST), determined by the particular parameters of the situation and the translation goal and, with the character of the translator's professional behavior in mind (Sdobnikov, 2011: 1450). To put it simply: any act of translation should be viewed in the context of the communication environment that includes the author of the ST, or Sender, the receivers (recipients) of the ST, the translator, and the recipients of the TT (communication actors). The communication actors not only communicate; they also interact when involved in some practical activity. It is very important to realize that they communicate because they need to make this practical activity done. So, they have some aim in view, and the translator's task is to comprehend what their aim is, and to realize the translation goal. The latter will determine what kind of translation strategy must be used to help the communication actors achieve their goal. Undoubtedly, the term "appropriate translation strategy" implies the strategy conformity to the characteristics of the communicative situation as well as the needs and expectations of the TT recipients. It should be noted, in passing, that interaction between the "trio" (the ST sender, the translator and the TT recipient) can be both indirect and direct, depending on the specificity of the communicative situation under review.

Given the communicative situation characteristics of translation (CST) in selecting a translation strategy and determining the translation goal are so important, we have attempted to catalogue CSTs at hand. The classification differentiates between two classes of CSTs - those in which translation is intended and foreseen initially, i.e. at the very beginning of the communication process, at the moment of the ST production; and those in which translation is not intended or foreseen initially. Accordingly, the names of the said classes of communicative situations are abbreviated as CST-1 and CST-2.

Though communicative situations of translation are manifold, they can be grouped into a finite number of types within each of the classes. Even less is the number of translation strategies applied to those CSTs. We have established three types of translation strategies, namely: the strategy of communicatively equivalent translation, the strategy of tertiary translation and the strategy of redirection (Sdobnikov, 2015). The first of the three strategies implies reproducing ST in such a way that the communicative intention of its Sender is realized in the TT. The strategy of tertiary translation is used when the translation goal differs from the 
one which has supported the ST creating, and the translation proper emerges in the interests of the third person(s) not involved - directly or indirectly - in the communication process (see, for example, (Sdobnikov, 2013)). Below, I shall try to reveal the gist of the redirection strategy and describe the situations in which this type of translation strategy is most appropriate.

\section{Strategy of Redirection: Definition}

My definition of redirection strategy runs as follows: it is a general program of a translator's activity aimed at producing a TT addressed to the recipient(s) who differ(s) from the ST recipients not only in the national identity but also in certain social characteristics. The most prominent social characteristics which make the ST and TT audiences so different include age and education.

In practice, a translator/interpreter occasionally faces situations when a ST produced for the audience with certain social characteristics must be translated or interpreted for the audience with different social characteristics. The strategy of communicatively equivalent translation obviously fails to be applied in such situations: the TT that is similar to the ST in terms of composition, syntax, lexis and stylistic peculiarities could hardly be comprehended by the target audience completely due to the lack of specialized or background knowledge. Given the audience's cognitive possibilities, the text needs to be adapted to the target audience needs and expectations. This is achieved by using the redirection strategy, whose gist can be formulated in the following way: the text being translated or interpreted is "turned in the direction" of another audience which differs from the initial one; it is redirected. At the same time, the adaptation of the text serves to realize the Sender's communicative intention in some cases or to realize the purpose of the translation/ interpreting initiator, or commissioner, in other cases. Ch. Nord argues that "initiators may have communicative purposes of their own or they may share those of either the sender or the receiver" (Nord Ch., 134). In this respect the redirection strategy does not differ much from the strategy of communicatively equivalent translation. It is the communicative effect produced by the TT that is slightly different from the effect produced by the ST. The content and the meaning of the text may be comprehended in full by the target audience (to the extent they are reproduced in the TT) but there are some nuances that can remain concealed from the TT recipient.

An explanation is needed as to why I have previously used the term "adaptation" in reference to the strategy being discussed. The term is widely used in Translation Studies, and means such modification of the text which is necessary for accommodating it to the perception of the target audience belonging to another culture. Therefore, the need for "pragmatic adaptation" is due to the cultural differences between the ST recipients and the TT recipients. Olga Petrova claims that when pragmatic adaptation is made "a translator either supplies the information that can remain unperceived by the TT recipient because of some cross-cultural differences, though it is easily deciphered from the ST by its recipient, or uses other means to level out the differences in the background knowledge of the ST Sender, on the one hand, and the TT recipient, on the other (translation mine. - V.S.)" (Petrova, 2010: 20). It was Olga Petrova who has proposed that another term should be used to denote a translator's actions in the situation when the translation is addressed to the target audience which is different from the ST audience not only in its national and cultural identity but also in some social characteristics (Petrova, 2010: 20). And the term is "redirection". As I share this opinion and draw a hard and fast line between the two types of a translator's 
actions, I have to admit that I have used the term "adaptation" in a non-terminological meaning, by extension, to simplify the narration.

Indeed, the two types of a translator/ interpreter's activities are entirely different in nature. As follows from Olga Petrova's arguments, the term "adaptation" applies to the cases when some culturally specific information is modified to make it comprehensible to the TT audience which differs from the ST audience in its cultural background. Such modifications can be limited to some "spots" in the text. On the contrary, redirection has scope and location: it embraces the text as a whole, and redirecting modifications are located at all language levels - at the level of lexis, syntax and the text composition.

It should be noted that the double term "translation/interpreting" referring to written translation and oral interpretation is used deliberately to demonstrate that the strategy of redirection can be used in the situations when interpreting is made as well as in the situations when translation is made. The two types of a translator's activities (translation and interpreting) broadly correlate with the two classes of communicative situations, namely, CST-2 and CST-1 respectively.

\section{Strategy of Redirection in Translation}

In my opinion, translation is made mostly in CST-2, i.e. in situations when a commissioner initiates translation of a text some time after the text was produced. The list of probable commissioners of translation may include the ST Sender, the TT recipient, the Buyer of translation and the translator. The Buyer is a person or organization which needs translation as a means to ensure some substantive activity. A publishing house can serve as an example of such a commissioner. It is clear that the publishing house's manager places an order for the translation not because (s)he wants his/her personal needs to be satisfied but because the translation is required for the purpose of continuing the publishing house's production activity. The manager does not act as the end user of the TT (as is the case with the TT recipient).

The strategy of redirection is used for making translation only in two communicative situations: $\quad$ CST- $2_{\text {buyer }}(\mathrm{LT})$ and CST- $2_{\text {buyer }}(\mathrm{ST})$, where "buyer" stands for the commissioner of translation, LT means "literary text" while ST means "specialized text".

True, examples of using the strategy of redirection in translation are not numerous. The translations of Jonathan Swift's "Gulliver's Travels" made by Tamara Gabbe and Daniel Defoe's "Robinson Crusoe" made by Korney Chukovsky seem to be the most illustrative cases of redirection in translation from English into Russian. The both translations have been made for children, i.e. for the audience with a different social characteristic (age). Due to the use of the strategy of redirection the communicative effects produced by the originals and the translations cannot be similar. Experts say that "Gulliver's Travels reflects conflicts in British society in the early $18^{\text {th }}$ century. By narrating about Gulliver's adventures in Lilliput, Brobdingnag, Laputa, and Houyhnhnm, the novel reveals and criticizes sins and corruption of British ruling class and their cruel exploitation towards people of Britain and neighboring countries in the capital-accumulation period of British history" (Gulliver's Travels...). This satirical content of the book can hardly be perceived by the young readers of the Russian translation because it has been eliminated. "Robinson Crusoe" has not been written for children either. Its philosophical meaning is expressed explicitly by the Guardian's independent journalist in the following way: "Defoe ... has Crusoe proceed toward the spiritual (or, it may be, superstitious) 
life of humanity, and convert from a thoughtless, wayward young man who had no interest in the meaning of his existence, to one who understands the need the vulnerable have for a personal god" (Diski, 2004). Korney Chukovsky has completely annihilated this spiritual meaning of the book in his translation, yet the communicative intention of the author has been preserved. At least, partially.

CST- $2_{\text {buyer }}(\mathrm{ST})$ is the situation in which a specialized text written for experts in a certain field is translated for the audience of nonspecialists. The translation may be published in a popular journal to narrate about some achievements in science and technology. Examples of the kind are not well-known but still are more than possible and most probable. If one says that the assumption is hypothetical, (s)he is probably right. This means, though, that a more thorough investigation into the matter is required to find evidence and appropriate illustrations of the use of the strategy of redirection in the given communicative situation.

\section{Strategy of Redirection in Interpreting}

Translation is not the only activity which allows the use of the strategy of redirection. Interpreting is the other one, though the majority of translation scholars would never admit it. Indeed, it is generally believed that interpreting is done "here and now", and the parties involved in the inter-lingual and inter-cultural communication interact as equals, which is not always the case. True, in the majority of CST-1 situations which include official and business talks, presentations, interviews, round tables, escorting, interpreting during sightseeing, actors have the same social and professional status, similar background knowledge and similar cognitive abilities. But there is a CST-1 that differs from other types of CST-1 situations, namely the situation of contract supervision, i.e. the situation of installation of some technical equipment under the supervision of a foreign specialist. In this case the workers on the site may experience some lack of technical knowledge due to the lack of specialized education.

It is noteworthy that the term "contract supervision" which I use arbitrary may be applied to a broader range of communicative situations. Whenever a foreign orchestra director conducts a rehearsal or a master-class, the situation may be treated as that of contract supervision with good reason. Whenever a foreign coach is training a football team, it is also a situation of contract supervision. But these are situations in which the actors are expected to have similar or almost similar background and professional knowledge, and the cognitive abilities of the both parties involved do not prevent them from communicating successfully (provided good interpretation is made by the interpreter).

Attention must be focused on those situations when, as I have pointed out earlier, the actors differ in their cognitive abilities. I can adduce the following example. An engineer has been invited from abroad to help install brandnew equipment for glass production at one of Russian plants. While talking to the personnel responsible for performing certain technical operations, he used purely technical language in his explanations as to what operations must be performed, how they should be performed and, what is most peculiar in the situation, why they should be performed. Dwelling on the latter aspect, the engineer went into many sadistic details concerning the chemical and physical processes occurring in the equipment during its installation, inspection, testing, etc. It goes without saying that the personnel were unable to comprehend the explanations which seemed unnecessary for them. The communication was ineffective, and the installation process was hindered by many instances of misunderstanding. 
It went on till another interpreter was to change his colleague. The second interpreter's decision was quick and wise: he started to omit unnecessary details providing the workers with only that information which was required to perform operations effectively. In general, the interpreter simplified the text as much as possible to make it comprehensible to the personnel.

In this example what the interpreter used was the strategy of redirection: the text was readdressed to another audience, which only helped to improve the technical process.

It might seem that the situation described is kind of "marginal", rare, an almost exceptional one. I believe that a closer insight into a larger number of communicative situations in which interpreting is made will help us discover more instances when the strategy of redirection must be used. It can be expected that legal interpretation in courts and law enforcement agencies is frequently done with the use of this strategy. The reasoning for this assumption is as follows: not infrequently one of the actors in inter-lingual and inter-cultural communication not only represents another culture (which is quite normal for all situations of translation/interpreting) but lacks specialized legal knowledge and, therefore, is unable to understand what is said to him or asked. Moreover, his social status is usually inferior to that of the other party (a judge, an investigator, a migration official, etc.); due to this fact (s)he can feel bewildered in the formal situation. Cecilia Wadensjö argues that "one can distinguish between those who get their position from the stronger structure, who would be installed to guarantee its normative system, and those whose role is the result of initiatives taken by the weaker one" (Wadensjö, 1998: 6263). Tentatively, I can conclude that the strategy of redirection might be required in many situations of the so called community interpreting. But, again, further investigations are needed to prove it.

\section{Conclusion}

The strategy of redirection is a general program of a translator's activity aimed at producing a TT addressed to the recipient(s) who differ(s) from the ST recipients not only in the national identity but also in some social characteristics. Though it is generally believed that this strategy is used in a limited number of communicative situations, a more closer observation over translators/interpreters' activities demonstrates that it may be used in a large variety of situations or even must be used to ensure a successful performance of the substantial activity by the communication actors. One should bear in mind that translation/interpreting is made because it is needed and expected. When this simple idea becomes predominant in Translation Studies and in translators' minds, the choice in favor of the strategy of redirection will be easier and more justified.

\section{References}

Diski, Jenny. (2004). "Survival Instinct”, Available at: https://www.theguardian.com/books/2004/ jul/17/classics.danieldefoe

Fernández Guerra, Ana. (2012). "Translating Culture: Problems, Strategies and Practical Realities”, In The Art and Subversion, 1, 12/2012, 1-27.

Gulliver's Travels by Jonathan Swift. Analysis of Satire, Available at: https://www.ukessays.com/ essays/english-literature/satires-in-gullivers-travels.php

Komissarov, Vilen N. (2001). Modern Translation Studies. Moscow, ETS.

Nord, Ch. "Translating as a Purposeful Activity: A Prospective Approach", Available at: https://kupdf. com/download/christiane-nord-translation-as-a-purposeful-activity_59050164dc0d60dc64959e9d_pdf 
Petrova, Olga. (2010). "Pragmatic Adaptation and Redirection in Translation", In Problems of Translation and Translation Theory, 13, 17-23.

Sdobnikov, Vadim V. (2011). "Translation Strategy Revised: The Communicative-Functional Approach", In Journal of Siberian Federal University. Humanities \& Social Science, 4 (10), 1444-1453.

Sdobnikov, Vadim V. (2015). Translation and Communicative Situation: Monograph. Moscow, Flinta-Nauka.

Sdobnikov, Vadim V. (2013). "Translation Tactics as Means of Implementing the Strategy of Tertiary Translation", In Modern Linguistic and Methodical-and-Didactic Researches: Scientific Newsletter, 1(2), 109-117.

Volkova, Tatiana. (2010). Discourse-Communicative Model of Translation. Moscow, FlintaNauka.

Wadensjö, Cecilia. (1998). Interpreting as Interaction. New York: Addison Wesley Longman Ltd.

\section{Стратегия переадресации: что это такое?}

\section{В.В. Сдобников}

Нижегородский государственный лингвистический университет им. Н.А. Добролюбова Россия, 603155, Нижний Новгород, ул. Минина, 31 а

В статье исследуются коммуникативные ситуации перевода с использованием стратегии переадресации. Предлагается определение стратегии переадресации и разъясняется ее сущность. На основе коммуникативно-функиионального подхода к переводу рассматриваются конкретные примеры использования данной стратегии в письменном и устном переводе.

Ключевые слова: стратегия переадресации, письменный перевод, устный перевод, коммуникативно-функииональный подход.

Научная специальность: 10.02.00 - лингвистика, 24.00.00 - культурология. 